\title{
A HIGH POWER CHEMICAL OXYGEN IODINE LASER
}

\author{
Y. LOUVET, B. BARNAULT, E. GEORGES and D. PIGACHE \\ Office National d' Etudes et de Recherches Aérospatiales, BP. 72, F-92322 Châtillon cedex, France
}

\begin{abstract}
Optimization tests are being conducted on a high power chemical oxygen iodine laser. Optical diagnostics were developed to monitor variations in laser medium species. Presently 570 watt laser output was obtained and a laser power of at least one kilowatt is expected.
\end{abstract}

\section{1 - Introduction}

The chemical oxygen iodine laser (COIL) has a $\mathrm{CW}$ high power capability(1,2). It emits at $1.315 \mu \mathrm{m}$ on an atomic iodine electronic transition. The upper level of laser transition $I^{*}\left({ }^{2} \mathrm{P} 1 / 2\right)$ is excited by collisional energy transfer from the oxygen metastable state $0_{2}\left({ }^{1} \Delta\right)$ which is chemically generated. The $1.315 \mu \mathrm{m}$ wavelength has excellent atmospheric and optical fiber transmission properties ${ }^{(3)}$. The COIL systems are interesting for many industrial, military and aerospace applications.

\section{2 - Description of the experimental set-up}

The COIL system (figure 1) consists of a bubble column singlet oxygen generator, a water vapor cold trap, a rectangular duct laser cavity, an iodine heater and injector system, a liquid nitrogen trap and a group of Roots pumps. The bubble column, $600 \mathrm{~mm}$ in diameter, contains an aqueous solution of $\mathrm{H}_{2} \mathrm{O}_{2}\left(85 \%, 20 \mathrm{dm}^{3}\right)$ and $\mathrm{NaOH}\left(6 \mathrm{~N}, 15 \mathrm{dm}^{3}\right)$. Chlorine gas is introduced into a drilled plate (at a maximum flow rate of $0.3 \mathrm{~mole} / \mathrm{s}$ ) and then bubbled through the reactive solution. The bubbler plate, $500 \mathrm{~mm}$ in diameter, has 1000 holes each $2 \mathrm{~mm}$ in diameter. The water vapor trap is composed of two spiral tube heat exchangers, each $300 \mathrm{~mm}$ in diameter, with a total exchanger surface of $5 \mathrm{~m}^{2}$ and a typical operating temperature of $-40^{\circ} \mathrm{C}$. The laser cavity has a rectangular flow channel of $150 \times 6 \mathrm{~cm}^{2}$. The typical flow velocity is $50 \mathrm{~m} / \mathrm{s}$. The optical cavity can be used in singular or multipass arrangement to provide gain lengths of 1.5 or $4.5 \mathrm{~m}$. To obtain the nominal pressure of 1 Torr in the laser cavity, a nitrogen buffer gas is often used. The iodine vapor is injected at a distance of $14 \mathrm{~cm}$ in front of the optical axis. In order to obtain a reliable iodine flow rate with good $0_{2}-I_{2}$ mixing, a new iodine system has 
been developed(4). Iodine vapor is produced by sublimation of several thin iodine plates in vitreous phase. The iodine plates provide a total sublimation surface of $2500 \mathrm{~cm}^{2}$. Fifteen iodine plates are distributed between five iodine heaters. The iodine heaters, of the double boiler type, are water heated to a temperature between $45^{\circ} \mathrm{C}$ and $70^{\circ} \mathrm{C}$ (see figure 2). The iodine flow rate depends on the water temperature (which remains constant during testing) and an adjustable gas flow which is introduced into the heater. The iodine injector system inside the laser cavity consists of 75 nickel tubes positionned $19 \mathrm{~mm}$ apart. Each tube, $6 \mathrm{~mm}$ in diameter, is drilled with two rows of eleven $0.3 \mathrm{~mm}$ holes. The direction of the iodine injection is positionned at a $45^{\circ} "$ angle in the direction of the oxygen flow (figure 3). The liquid nitrogen trap, with seven cold fingers, has a diameter of $1.2 \mathrm{~m}$ and a total exchanger area of $7 \mathrm{~m}^{2}$. The vacuum pump system consists of a series of adjustable-speed Roots pumps, with a maximum pumping speed of $18000 \mathrm{~m}^{3} / \mathrm{h}$ for pressures varying from 1 to 10 Torr. A numerical model and optical diagnostics have been developed to monitor variations in 1 aser medium species ${ }^{(5.6)}$.

\section{3 - Optical diagnostics}

Several optical diagnostics are used to measure the iodine vapor, singlet oxygen residual chlorine and water vapor concentrations.

The iodine vapor concentrations are monitored in the laser cavity by absorption at $520 \mathrm{~nm}$ (filtered white light) with an absorption lenth of $3 \mathrm{~m}$ (figure 1, position C). Absorption percentage rates were measured at several heater temperatures as a function of the iodine heater nitrogen flow rate (figure 4). Absolute values of iodine flow rates can be deduced from the iodine absorption rate ${ }^{(7)}$. This result has been verified by jodine weight loss at a water heater temperature of $55^{\circ} \mathrm{C}$. Both measurements gave iodine flow rate of $0.19 \mathrm{~g} / \mathrm{s}( \pm 10 \%)$. The quality of $0_{2}-I_{2}$ mixing has been checked by Laser Induced Fluorescence (LIF). The absolute singlet delta oxygen concentration (figure 1 , position $A$ ) is measured from the emission intensity at $1.27 \mu \mathrm{m}$ with calibrated Ge detectors. The sensitivity of the detectors was measured using a blackbody reference emission $1.27 \mu \mathrm{m}$. By absorption at $325 \mathrm{~nm}$ and using an absorption length of $1.5 \mathrm{~m}$, the residual chlorine concentration can be detected after the laser cavity (figure 1, position D). The water vapor concentration is deduced and calculated using a ratio between the emission intensities of $760 \mathrm{~nm}$ from $\mathrm{O}_{2}\left({ }^{1} \Sigma\right)$ and $635 \mathrm{~nm}$ from the $2 \times 0_{2}\left({ }^{1} \Delta\right)$ collision complex ${ }^{(4,8)}$. Emissions at 760 and $635 \mathrm{~nm}$ are detected with two photomultipliers (PM) preceded by two filters (figure 1 , position $B$ ).

By absorption at $325 \mathrm{~nm}$ and using an absorption length of $1.5 \mathrm{~m}$, the residual chlorine concentration can be detected after of the laser cavity (Fig. 1, positionl)

\section{4 - Tests}

Several parameters are adjustable during a test, specifically: the oxygen flow rate, iodine flow rate, vacuum pumping speed, and the buffer nitrogen gas flow rate. For each test, the water iodine heater temperature can be changed and the optical cavity characteristics can also be modified. At present, a total of twenty tests have been performed with the completed installation(4). For the time being, 
typical oxygen flow rates are $0.1 \mathrm{~mol} / \mathrm{s}$ with an iodine flow rate between $0.7 \%$ and $1.4 \%$ of the oxygen flow rate. A laser cavity pressure of 1 Torr has been obtained at the maximum pumping speed, by adding a large amount of buffer nitrogen gas. For the moment, excessive levels of water vapor concentrations have been noticed resulting in a low laser gain which has required the use of an output mirror with a 99\% reflectivity coefficient. Typical results from 500 watt testing expressed as a function of time are represented in figures $5 \mathrm{a}$ and $5 \mathrm{~b}$. A maximum output of 570 watt was obtained using a chlorine flow rate above $0.1 \mathrm{~mol} / \mathrm{s}$.

\section{5 - Conclusion}

Optimization tests are being conducted on a high power COIL system at ONERA. A new iodine heater and injector system has been developed and successfully tested. Optical diagnostics have also been developed to measure all laser medium species. Experiments are in progress and an output power of at least one kilowatt is expected.

This work has been supported by DRET (Direction des Recherches et Etudes Techniques).

\section{References}

[1] AVIZONIS, P., 7th G.C.L., Vienna, Austria, August 22-26, 1988.

[2] FUJII, H., YOSHIDA, S., LIGUKA, M., and ATSUTA, T., J. Appl. Phys., 67 (9), (1990), 3948.

[3] YOSHIDA, S., and SHIMIZU, K., 8th G.C.L., Madrid, Spain, September 10-14, 1990.

[4] BARNAULT, B. and al., 8th G.C.L., Madrid, Spain, September 10-14, 1990.

[5] BONNET, J., DAVID, O., GEORGES, E., LEPORCQ, B., PIGACHE, D., and VERDIER, C., 5th G.C.L., Oxford, England, August 20-24, 1984.

[6] DAVID, D., GEORGES, E., LEPORCQ, B., PIGACHE, D., and VERDIER, C., 6th G.C.L., Jerusalem, Israel, September 8-12, 1986.

[7] TELLENGHUISEN, J., J. Chem. Phys., 58 (7) (1973), 2821.

[8] BACAR, J. and ROSENWAKS, S., Appl. Phys. Lett., 41 (1) (1982), 16.

[9] FISK, G.A. and HAYS, G.N., J. Chem. Phys., 77 (10) (1982), 4965.

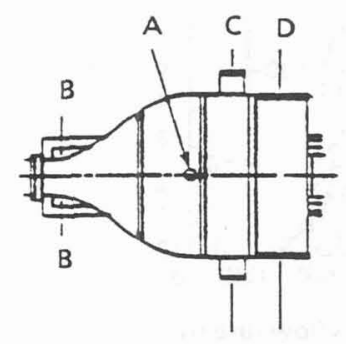

Under side laser-cavity

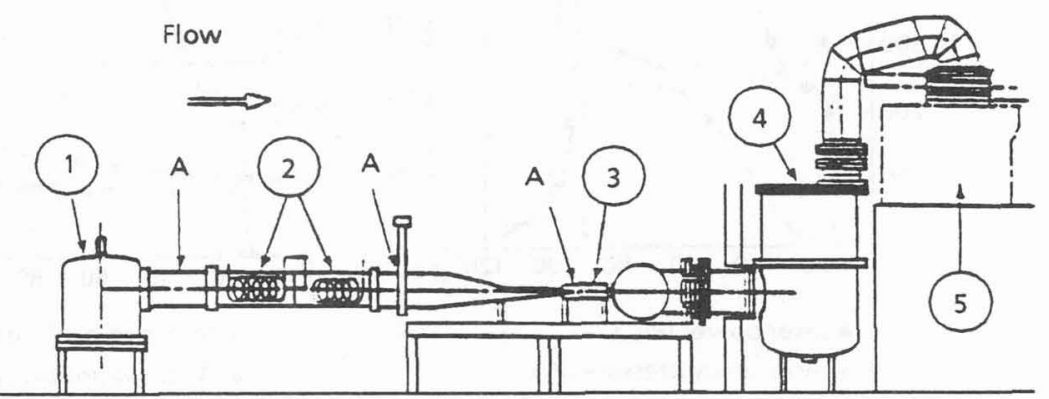

Fig. I - Schematic view of the experiment with positions of optical diagnostics. 1) Chemical generator 2) Water vapor cold trap 4) Liquid nitrogen trap 3) Laser cavity and iodine injection.

5) Vacuum pump system 


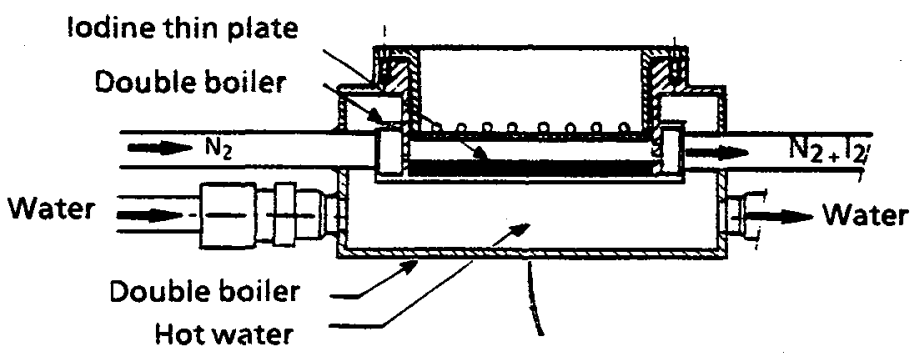

Fig. 2 - Schematic cut-away view of an iodine heater.
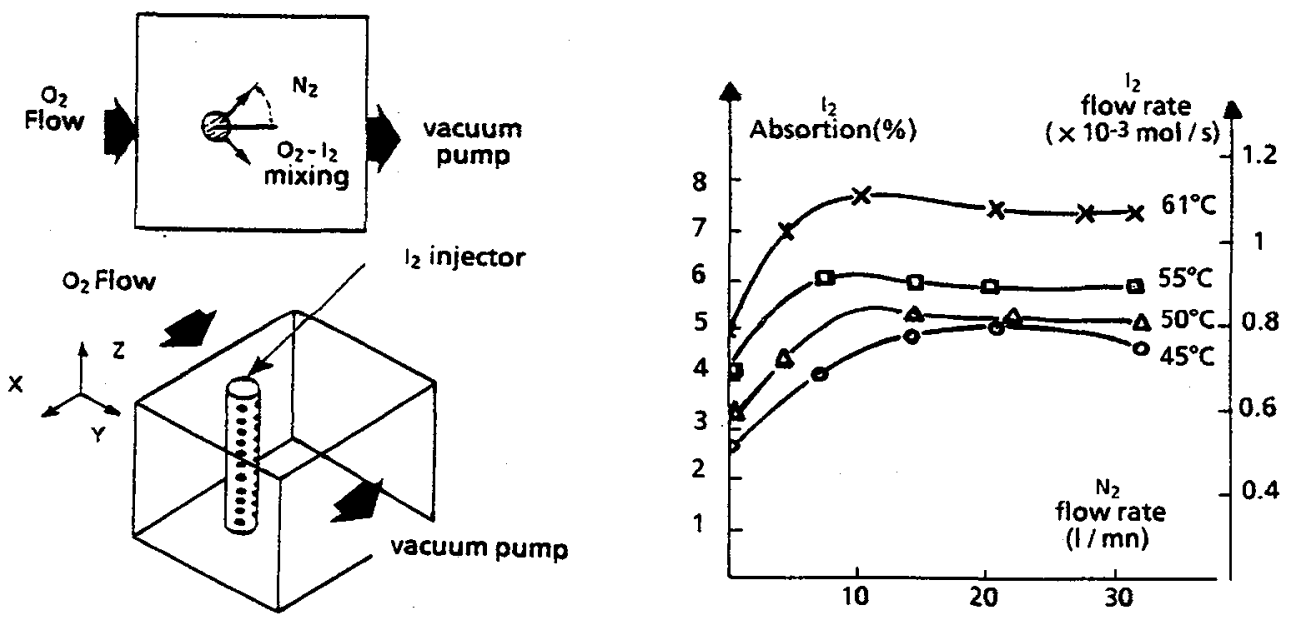

Fig. 3 - Schematic view of an iodine injector.

Fig. 4 - Variation of iodine absorption

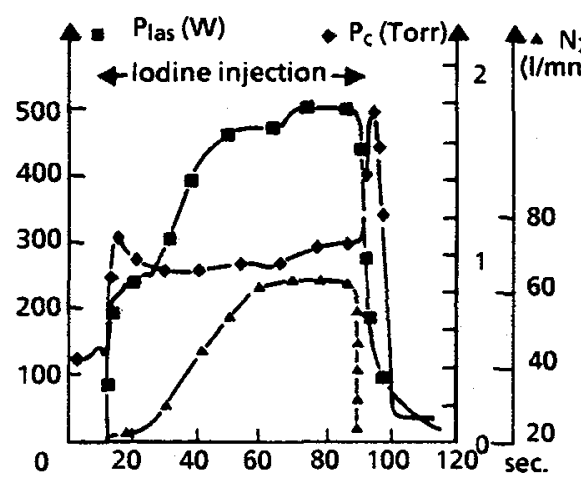

- Laser power (Plas)

- Laser cavity pressure $\left(P_{c}\right)$

- lodine heater nitrogen flow rate $\left(P_{c}\right)$

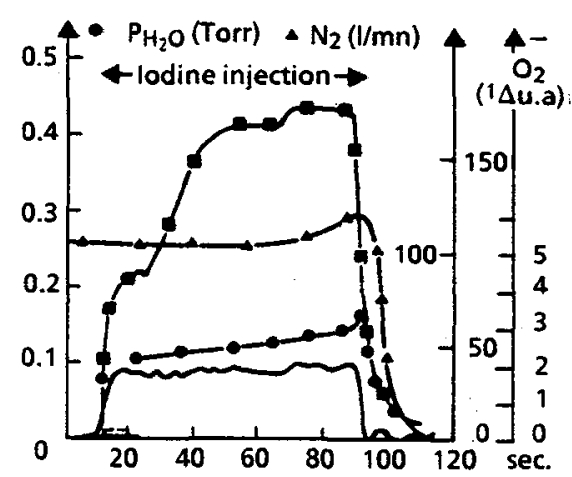

- Nitrogen buffergas flow rate $\left(\mathrm{N}_{2}\right)$

- Water vapor pressure $\left(\mathrm{P}_{\mathrm{H}_{2} \mathrm{O}}\right)$

- Singiet oxygen concentration $\left(\mathrm{O}_{2}\left({ }^{1} \Delta\right)\right)$

Fig. 5a and b - Variations in laser medium species as a function of time: Test conditions: $1201 / \mathrm{mn}$ chlorine flow rate $(0.084 \mathrm{~mol} / \mathrm{s})$, $18000 \mathrm{~m}^{3} / \mathrm{h}$ vacuum pumping speed, $55^{\circ} \mathrm{C}$ iodine heater temperature. 